\title{
DESENVOLVIMENTO DE REAGENTE REDUTOR DE UMIDADE DO PELLET FEED PARA A ETAPA DE FILTRAGEM NA SAMARCO MINERAÇÃO S.A.*
}

\author{
Alexandre Gonçalves Andrade ${ }^{1}$ \\ Allan Suhett Reis ${ }^{2}$ \\ Marco Antonio Zuchi ${ }^{3}$ \\ Adriano da Silva Marchezi ${ }^{4}$
}

\section{Resumo}

Com a queda na qualidade dos minérios de ferro das minas da região de Minas Gerais, torna-se cada vez mais necessárias maiores energias de moagem para a retirada de impurezas, tais como SiO2 e PPC (perda por calcinação). Este fato implica em maiores superfícies específicas do minério de ferro para a etapa de filtragem, com consequente perda de produtividade e aumento da umidade final da torta formada. Assim sendo, existe grande impacto deste teor de umidade na etapa de aglomeração (taxa de crescimento de pelotas) e na perda de produtividade dos fornos de endurecimento. Como alternativa para a redução do teor de umidade da torta do pellet feed na etapa de filtragem, avaliou-se a utilização de auxiliares de filtração (surfactantes) nas etapas de filtragem e pelotamento, tanto em teste em escala piloto e industrial.

Palavras-chave: Filtragem; Auxiliares; Surfactantes.

\section{PELLET FEED MOISTURE REDUCTOR REAGENT DEVELOPMENT FOR SAMARCO'S FILTRATION STEP}

\section{Abstract}

The decline of Minas Gerais iron ore quality, higher grinding energies are necessary to remove impurities, such as $\mathrm{SiO} 2$ and LOI (loss on ignition). It denotes in higher iron ore specific surfaces for filtration step, with consequent loss of productivity and increase of moisture on pellet feed. Therefore, this higher moisture level impact negatively in agglomeration step (pellet growth rate) and in furnace productivity. As an alternative to reduce pellet feed moisture in filtration step, was evaluated the utilization of filtration auxiliary in pilot and industrial scale.

Keywords: Filtration; Auxiliary; Surfactants.

1 Engenharia metalúrgica e de materiais, engenheiro, engenheiro de processo, departamento de engenharia de processo, Samarco Mineração SA, Anchieta, Espírito Santo, Brasil.

2 Engenharia metalúrgica, engenheiro, engenheiro de processo, departamento de engenharia de processo, Samarco Mineração SA, Anchieta, Espírito Santo, Brasil.

3 Tecnico em química, laboratorista, departamento de engenharia de processo, Samarco Mineração SA, Anchieta, Espírito Santo, Brasil.

4 Tecnico em química, laboratorista, departamento de engenharia de processo, Samarco Mineração SA, Anchieta, Espírito Santo, Brasil. 


\section{INTRODUÇÃO}

O processo produtivo da Samarco Mineração é composto por duas unidades, com $400 \mathrm{~km}$ de distância entre elas. A unidade de Germano (Minas Gerais) é constituída pela mina e as plantas de beneficiamento. $O$ transporte do minério de ferro concentrado é feito por minerodutos entre os estados de Minas Gerais e Espírito Santo. A unidade de Ubu (Espírito Santo) é composta pelas plantas de pelotização, estocagem e embarque de pelotas de minério de ferro. A Figura 1 apresenta o fluxo de produção de pelotas de minério de ferro.

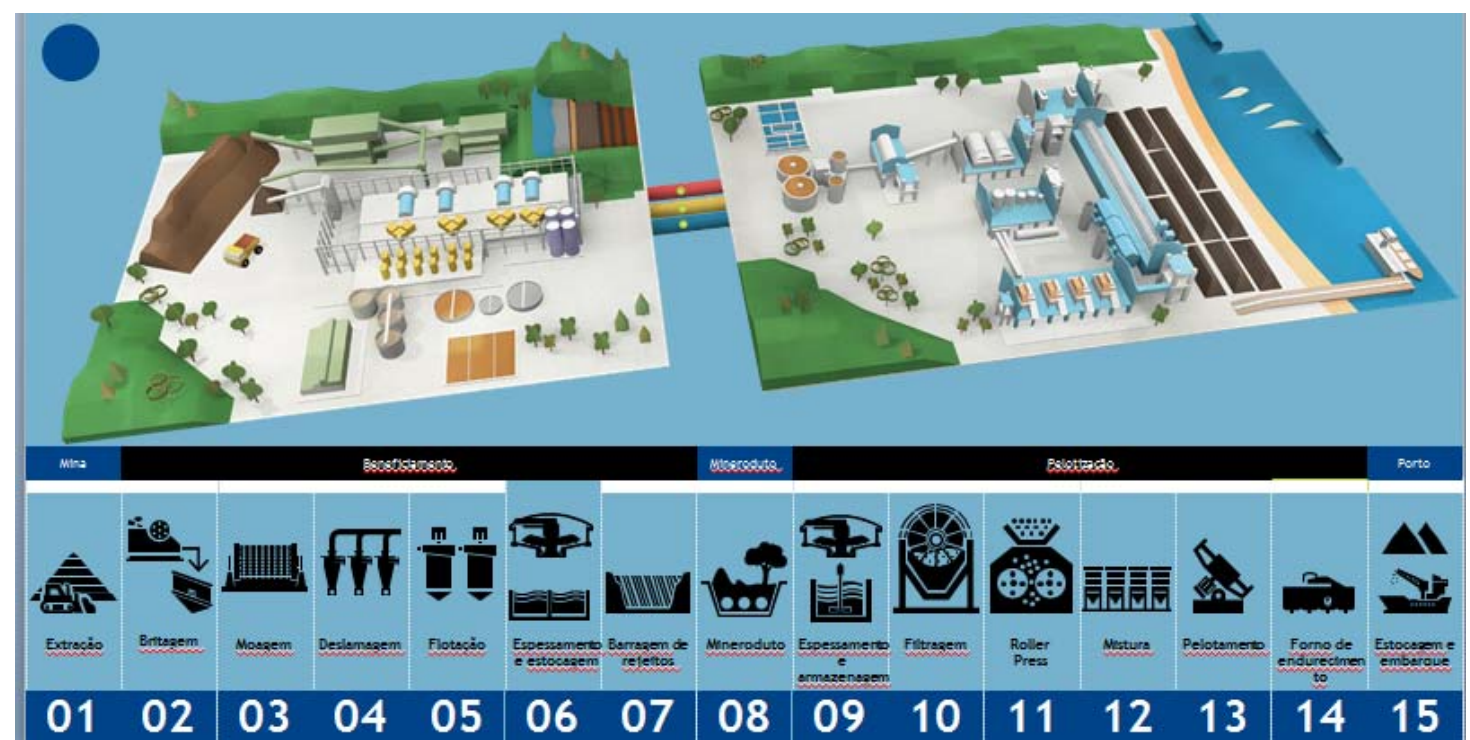

Figura 1: Processo produtivo da Samarco Mineração SA

$\mathrm{Na}$ etapa de extração de minério de ferro na mina, existe a tendência queda na qualidade do minério extraído (ROM - run of mine) ao longo dos anos, refletido em maiores teores de PPC (perda por calcinação) no concentrado final. Com isto, as etapas de concentração de minérios, que tem o objetivo de retirar as impurezas, precisam trabalhar com maiores energias de moagem. Assim sendo, a maior moagem gera maiores quantidade de materiais finos, ou materiais com maiores superfícies específicas.

A Figura 2 mostra a tendência de aumento do PPC e consequente aumento da superfície específica do pellet feed.

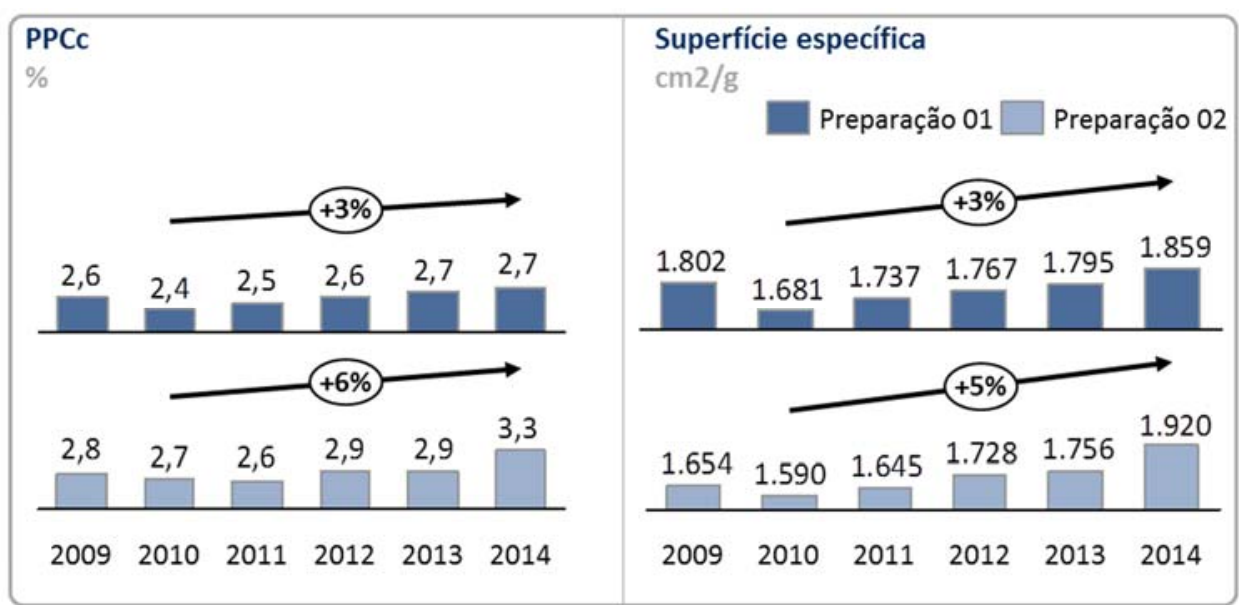

Figura 2: Histórico de PPCc e superfície específica. 
O impacto desta maior superfície específica do concentrado recebido na unidade industrial de Ubu é na etapa de filtragem, onde maiores valores provocam menor permeabilidade dos tecidos filtrantes, tendo em vista que os filtros utilizados na Samarco são filtros a disco horizontais. A consequência é uma redução da produtividade dos filtros e maiores teores de umidade do pellet feed (Figura 3).
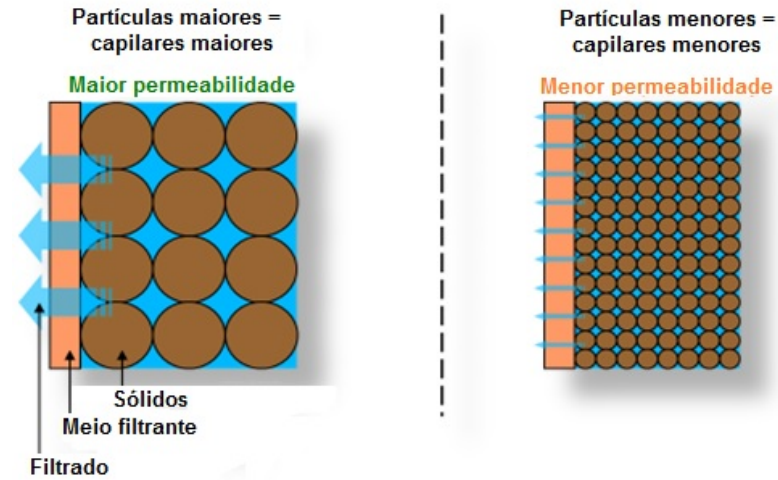

Figura 3: Permeabilidade do tecido com alta e baixa SE.

A Figura 4 apresenta o desempenho histórico da filtragem com relação à umidade do pellet feed. Verifica-se um aumento de umidade no ano de 2014, com alta correlação com o aumento de PPC e superfície específica.

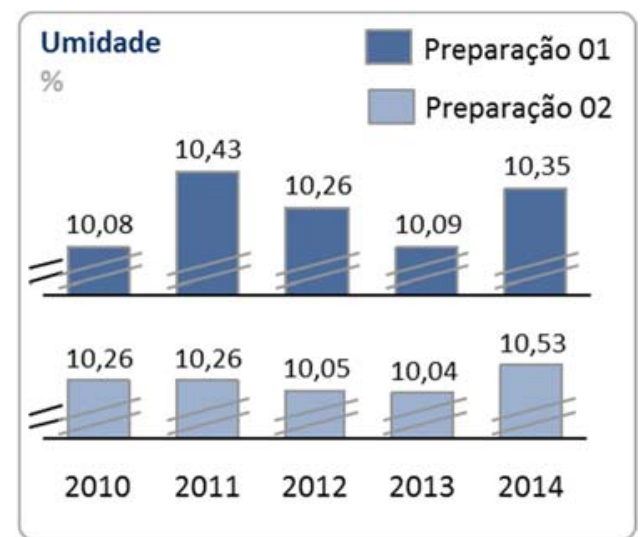

Figura 4: Histórico de umidade nas preparações

A superfície específica, conforme comentado no parágrafo anterior, tem alta correlação com a produtividade e umidade da filtragem (Figura 5).

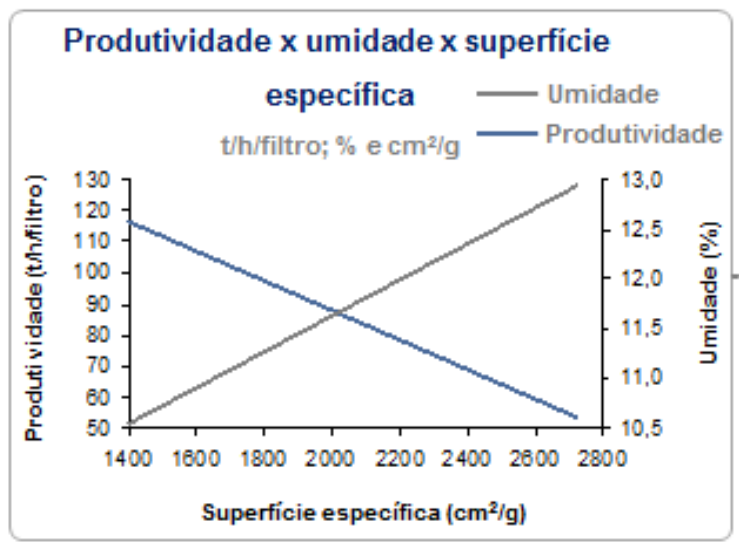

Figura 5: Impacto da umidade na produtividade. 
Em decorrência desse aumento de umidade, há um maior desafio na etapa de aglomeração, uma vez que há dificuldade no controle da taxa de crescimento de pelotas e tendência de queda da qualidade física da pelota crua. Se nada for feito, isso levará ao aumento da impermeabilidade do leito do forno e aumento da taxa de retorno no pelotamento (Figura 6).

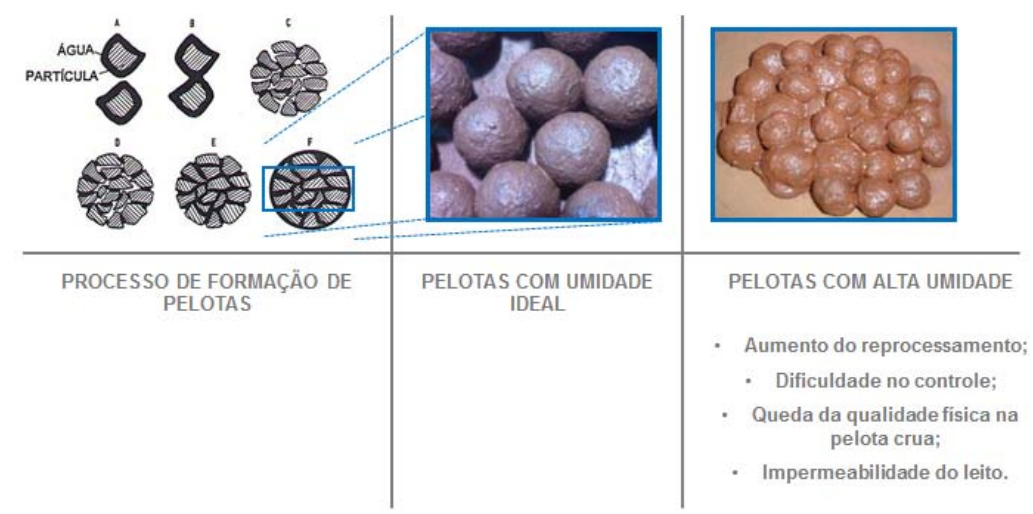

Figura 6: Impacto da umidade no pelotamento.

Como alternativa para reduzir a umidade do pellet feed na etapa de filtragem, decidiu-se estudar o uso de auxiliares de filtragem com o princípio dos surfactantes. Os reagentes auxiliares de filtragem, como os surfactantes, são de extrema importância no desaguamento de polpas contendo finos e ultrafinos. Diversos estudos têm sido desenvolvidos na busca de reagentes que sejam mais eficazes, que apresentem baixo custo e que possam reduzir a umidade das tortas formadas. ${ }^{(2)}$ A molécula do surfactante caracteriza-se por apresentar um caráter duplo: um ou mais grupos hidrofílicos (sulfonato, sulfato, carboxilato, etoxilato, entre outros) e um grupo hidrofóbico (cadeias hidrocarbônicas). Alguns surfactantes são tensoativos, sendo capazes de diminuir a tensão superficial do líquido por meio de uma interação com a superfície do mesmo. Essa interação levará a uma redução das forças de coesão existentes na superfície do líquido. O surfactante possibilita uma melhora no desempenho da filtragem, com o aumento da produtividade e uma redução da umidade do pellet feed produzido. (1)

Existem dois mecanismos principais de atuação dos surfactantes no desaguamento de polpas aquosas:

- Atuação na interface sólido/líquido, tornando a superfície do mineral hidrofóbica.

- Atuação sobre a interface líquido/ar, diminuindo a tensão superficial. Há, nesse caso, uma diminuição nas forças responsáveis pela retenção da água nos capilares da torta.

\section{MATERIAIS E MÉTODOS}

Os testes foram conduzidos no laboratório de separação sólido $\mathrm{x}$ líquido da Samarco Mineração. Foram avaliados quatro diferentes auxiliares de filtragem: A, B, C e D, (de dois diferentes fornecedores), através de testes em folha e testes de antiespumantes.

O teste em folha é realizado com o intuito de simular o desempenho de polpas no processo de filtração e, dessa forma, avaliar o comportamento das diferentes variáveis envolvidas neste processo. É possível também avaliar características do material a ser filtrado e dos insumos aplicados na filtração. As principais respostas 
dos testes em folha são a produtividade do filtro e a umidade final da torta formada. Para o teste são utilizados os seguintes materiais: Bomba de vácuo; Setor; Tecido; Balde; Kitassato; Mangueira; Manômetro; Válvulas de controle da linha; Suporte do setor; Luva de PVC; Espátula; Bandeja; Balança; Proveta de 1000 ml; Silicone; Abraçadeira; Cronômetro; pHmetro. A próxima figura apresenta o esquemático do teste em folha.
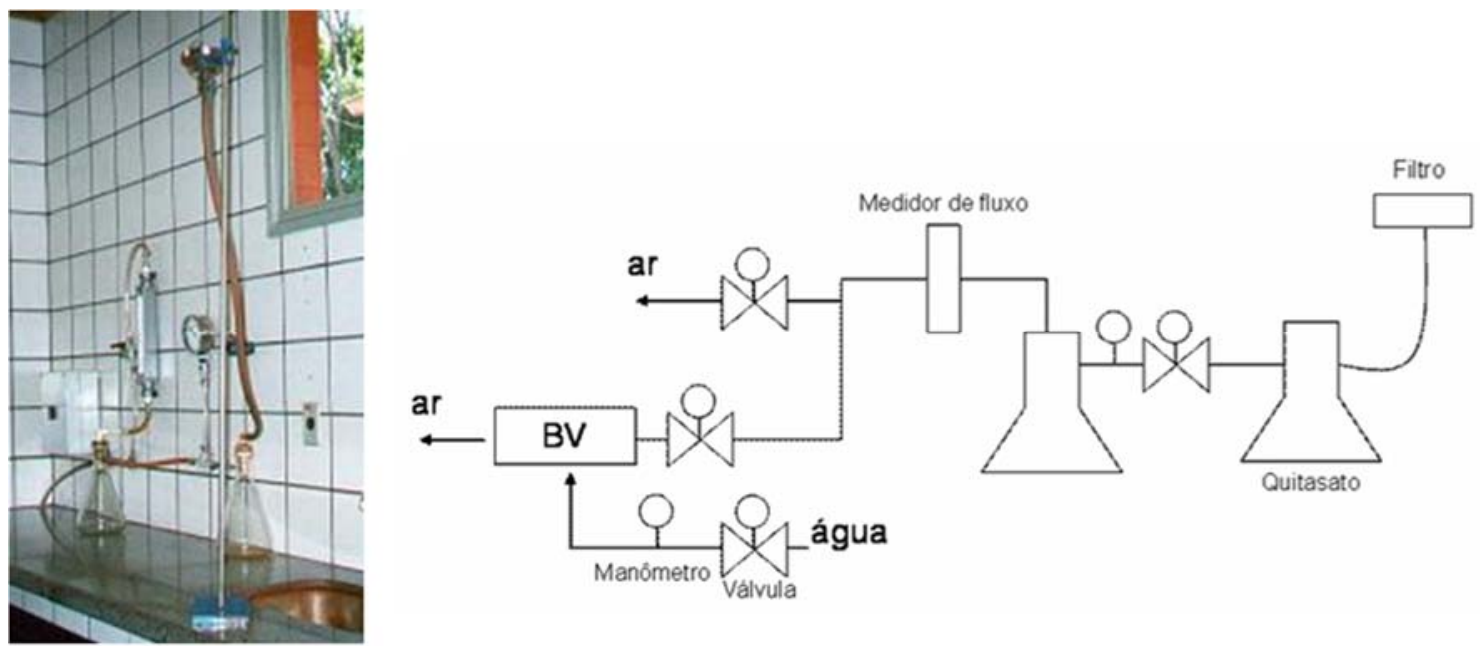

Figura 7: Imagem e desenho esquemático do teste de folha utilizado no estudo.

O teste de anti-espumante é feito para avaliar de forma qualitativa a eficiência de anti-espumantes ou o potencial de formação de espuma de um surfactante. Somente os produtos com melhores desempenhos no teste em folha foram testados em relação à formação de espuma. Esse teste consistiu na adição de surfactante em uma dosagem padrão em uma proveta de 1 litro, seguido de 40 agitações com plunger. O surfactante é reprovado nessa etapa se a formação de espuma for excessiva ou não desaparecer com o tempo.

Foram realizados testes de pelotamento em escala piloto, visando avaliar o impacto dos reagentes na aglomeração de minério de ferro.

Também foram realizados testes industriais, visando validar os resultados encontrados em escala piloto.

\section{RESULTADOS E DISCUSSÃO}

\subsection{Testes em Escala Piloto}

Inicialmente foram realizados testes em folha exploratórios, buscando obter respostas iniciais quanto aos quatro reagentes ensaiados. Nesta etapa foram utilizadas polpas de minério de ferro com superfície específica de $2.100 \mathrm{~cm}^{2} / \mathrm{g}, \mathrm{pH}$ na faixa de 11,5. O tempo de ciclo do filtro foi alterado em 80, 100 e 120 segundos e a dosagem dos reagentes foram de 0 (teste em branco), 30 e 50 ppm.

A Figura 8 apresenta os resultados do teste em folha exploratórios das amostras A, $\mathrm{B}, \mathrm{C}$ e D.

Pode-se perceber que as amostras A, B e C apresentaram queda na produtividade do filtro. Este efeito é indesejável, tendo em vista que etapa de filtragem é um gargalo do processo produtivo da Samarco Mineração. 
Já a amostra $\mathrm{D}$ apresentou a maior redução do teor de umidade entre os reagentes testados nesta etapa do desenvolvimento, sem impacto negativo na produtividade dos filtros (redução dentro da variação do processo).

Com base nestes dados, decidiu-se reprovar tecnicamente as amostras A, B e C e aprovar a amostra D.
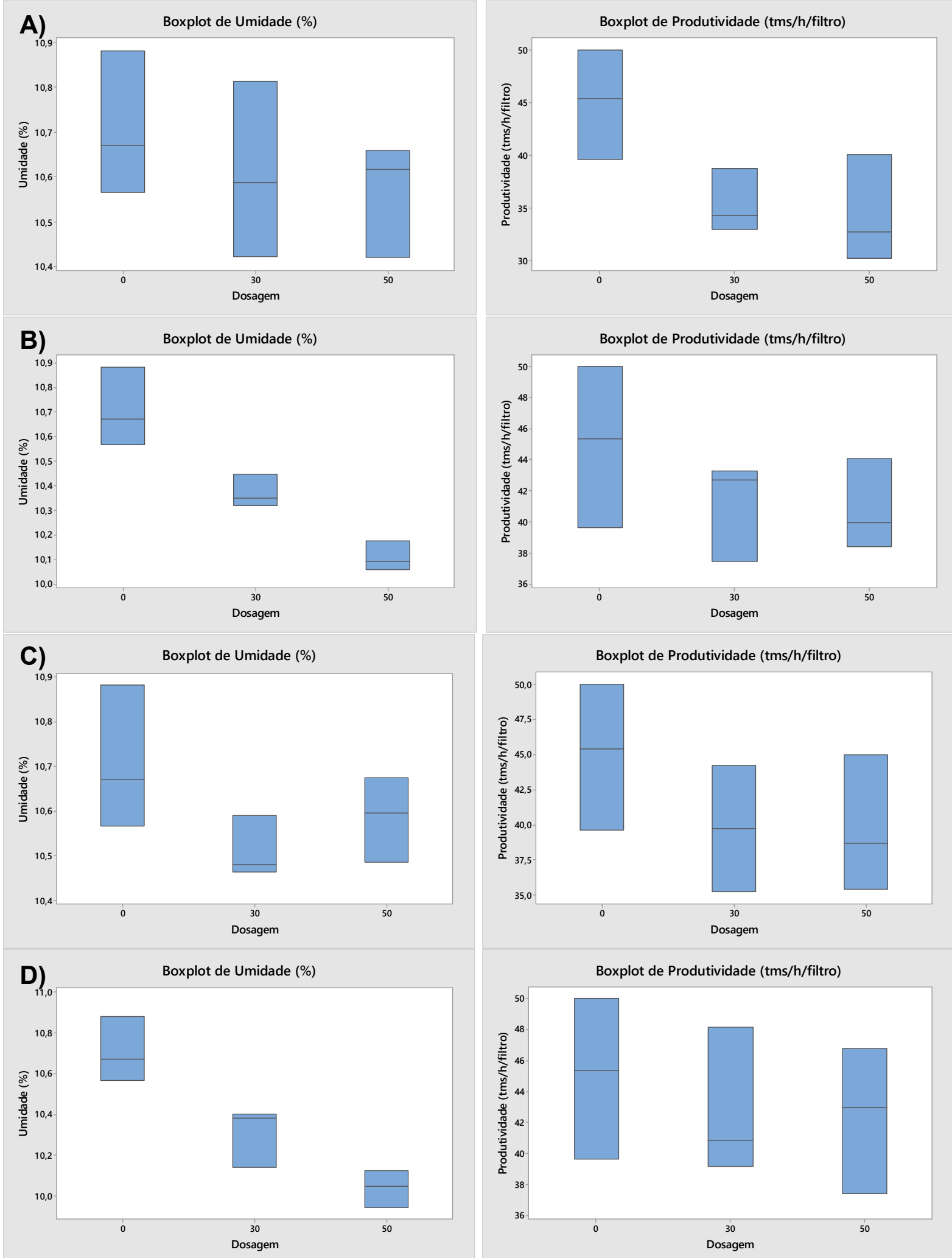

Figura 8: Tete em folha da amostra A, B, C e D. 
Após a etapa de testes exploratórios, foi realizado o teste de espumação do reagente aprovado tecnicamente nos testes em folha, visando avaliar a formação de espumas na etapa de filtragem. O efeito de formação de espuma é indesejável para a formação homogênea da torta de pellet feed nos tecidos filtrantes. A Figura 9 apresenta um exemplo de formação de espuma. $O$ reagente também foi aprovado nesta etapa de teste.

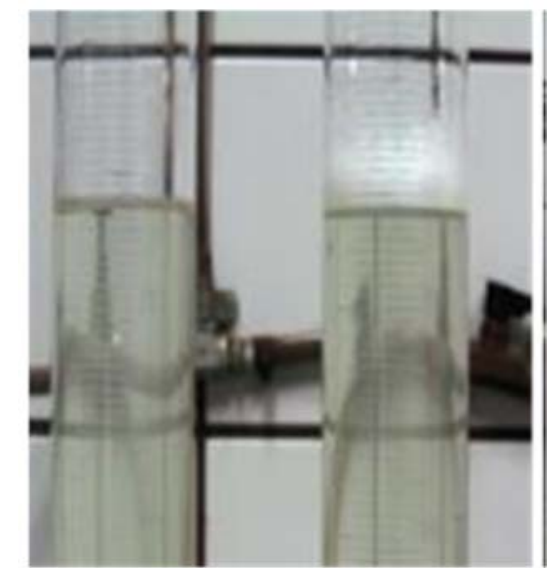

Figura 9: Exemplo de teste de espumação da amostra D.

Após o teste de espumação, o reagente aprovado nos testes exploratórios foi submetido a um projeto de experimento (DOE). Objetivou-se assim avaliar de forma completa os possíveis resultados industriais que o produto possa fornecer. A figura a seguir apresenta as condições em que o reagente foi ensaiado.

\begin{tabular}{|l|c|c|c|}
\hline Indicador & \multicolumn{3}{|c|}{ Condições de teste } \\
\hline Dosagem do reagente $(\mathrm{ppm})$ & 0 & 10 & 50 \\
\hline Superfície específica $\left(\mathrm{cm}^{2} / \mathrm{g}\right)$ & 1800 & 2100 & 2400 \\
\hline Densidade $\left(\mathrm{g} / \mathrm{cm}^{3}\right)$ & 2,1 & 2,3 & - \\
\hline $\mathrm{pH}$ & 11,00 & 11,50 & - \\
\hline Tempo de ciclo $(\mathrm{seg})$ & 80 & 100 & 120 \\
\hline
\end{tabular}

Figura 10: DOE com amostra D.

O resultado do DOE mostrou que a produtividade do filtro não foi afetada com a dosagem do reagente. A Figura 11 apresenta o resultado de todas as interações com a produtividade. 


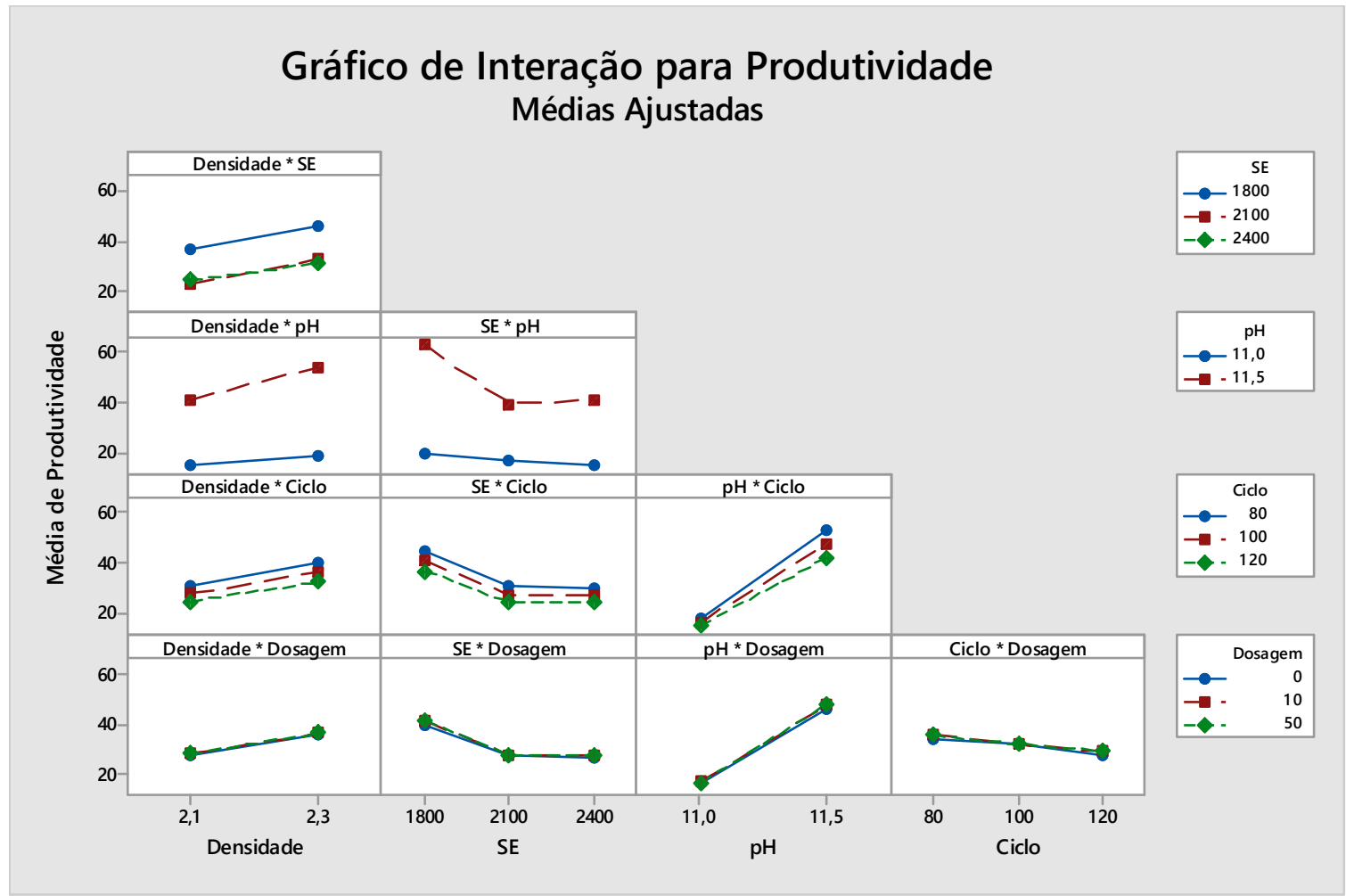

Figura 11: Gráfico de interação para Produtividade.

A Figura 12 apresenta o gráfico de efeitos principais para a produtividade, nele é possível verificar que a dosagem do reagente não afetou a produtividade dos filtros.

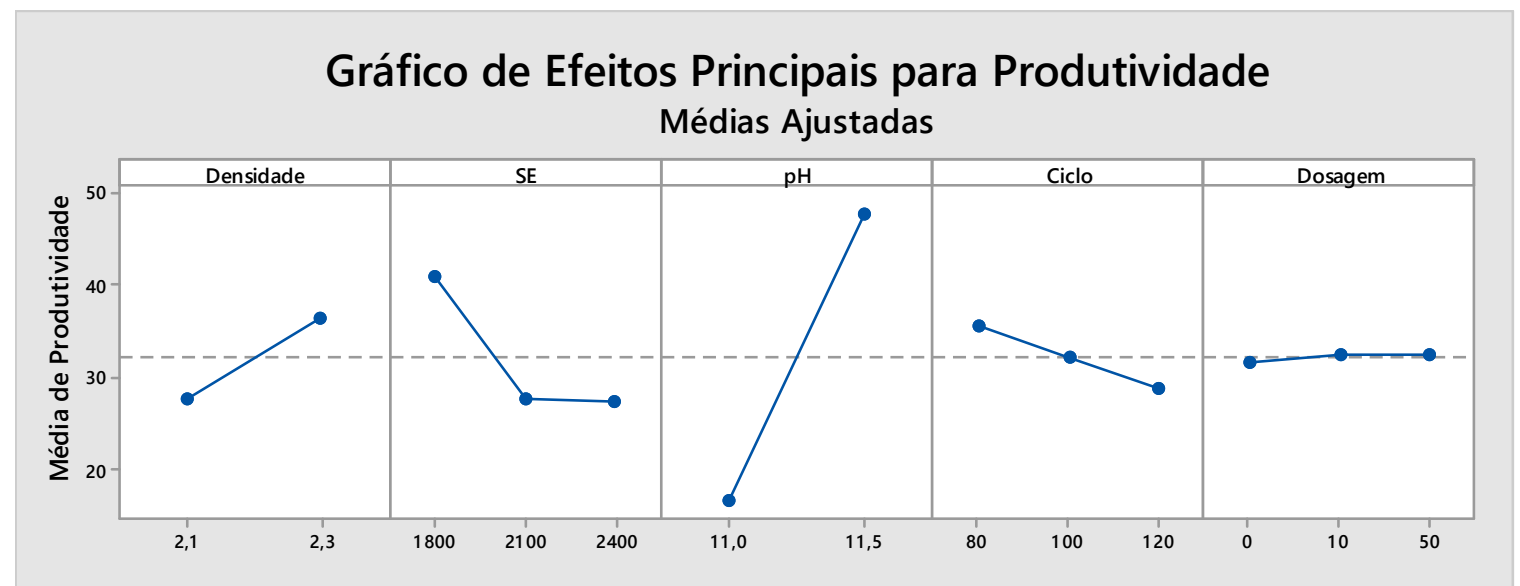

Figura 12: Gráfico de efeitos principais para produtividade.

A Figura 13 apresenta o gráfico de interação para umidade, onde é possível verificar que a dosagem do reagente reduziu a média de umidade da torta do pellet feed. 


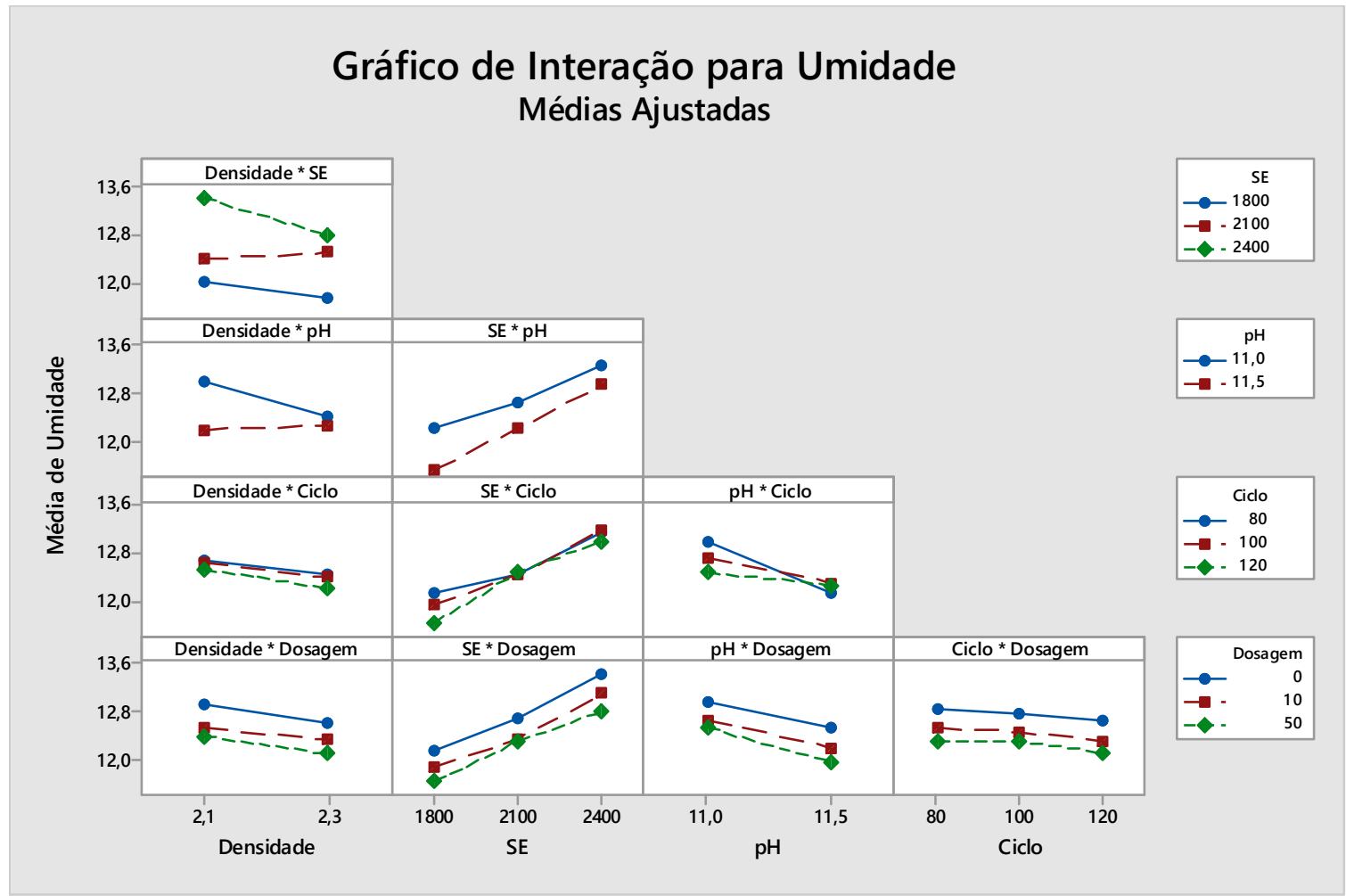

Figura 13: Gráfico de interação para umidade.

A Figura 14 apresenta o gráfico de efeitos principais para umidade, verifica-se que a dosagem do reagente reduziu a média de umidade do pellet feed.

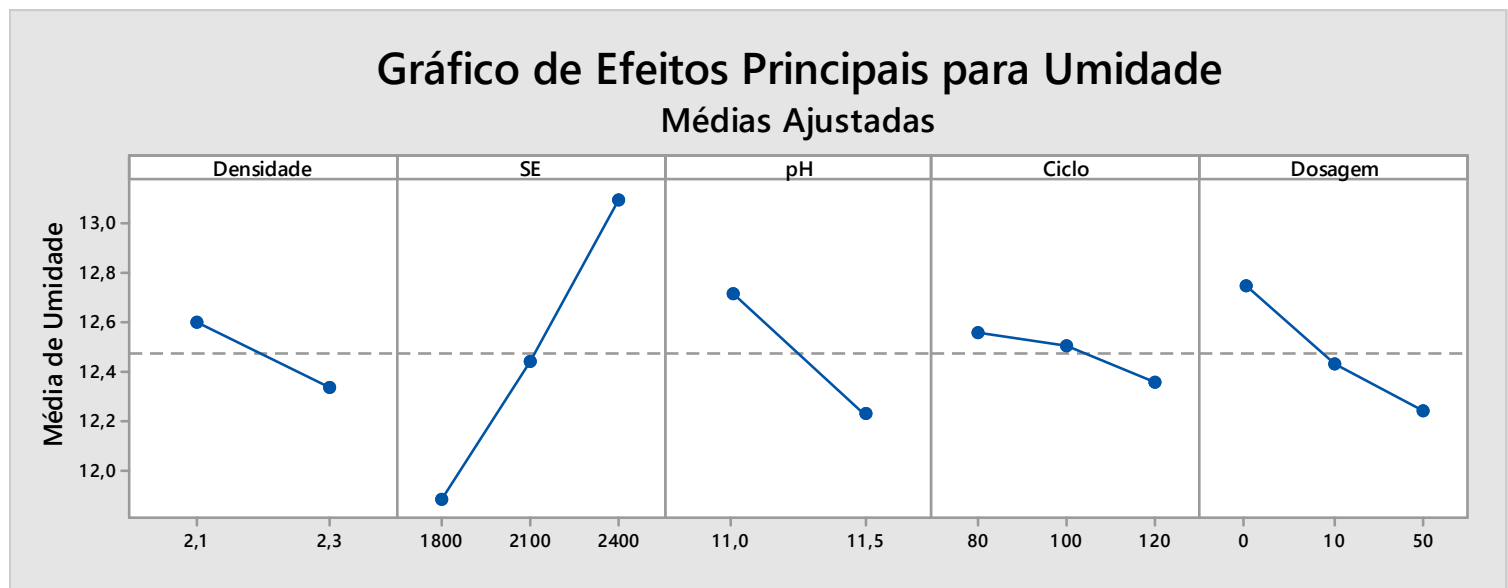

Figura 14: Gráfico de efeitos principais para umidade.

Para comprovação estatística dos resultados obtidos em testes em escala laboratorial, foi realizado o teste de normalidade para cada conjunto de dados nas superfícies específicas de 2.100 e $2.400 \mathrm{~cm}^{2} / \mathrm{g}$. 

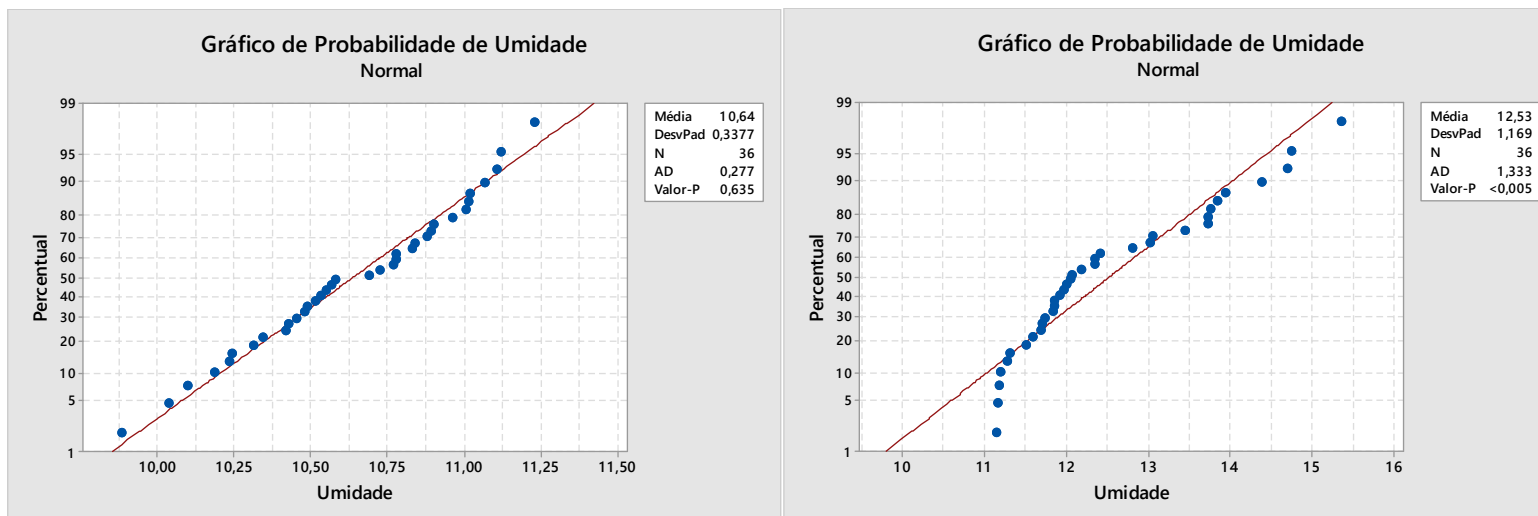

Figura 15: Teste de normalidade dos dados.

A análise de igualdade estatística entre os resultados de umidade e produtividade dos filtros para a superfície específica de $2.100 \mathrm{~cm}^{2} / \mathrm{g}$ mostrou que os resultados de umidade da torta são diferentes estatisticamente ( $p$-valor $<0,05$ ), comprovando assim o efeito do surfactante. Já os resultados de produtividade apresentaram pvalor $>0,05$. Com isto, conclui-se que existe igualdade estatística entre os resultados. Sendo assim, o reagente não impactou na produtividade dos filtros.
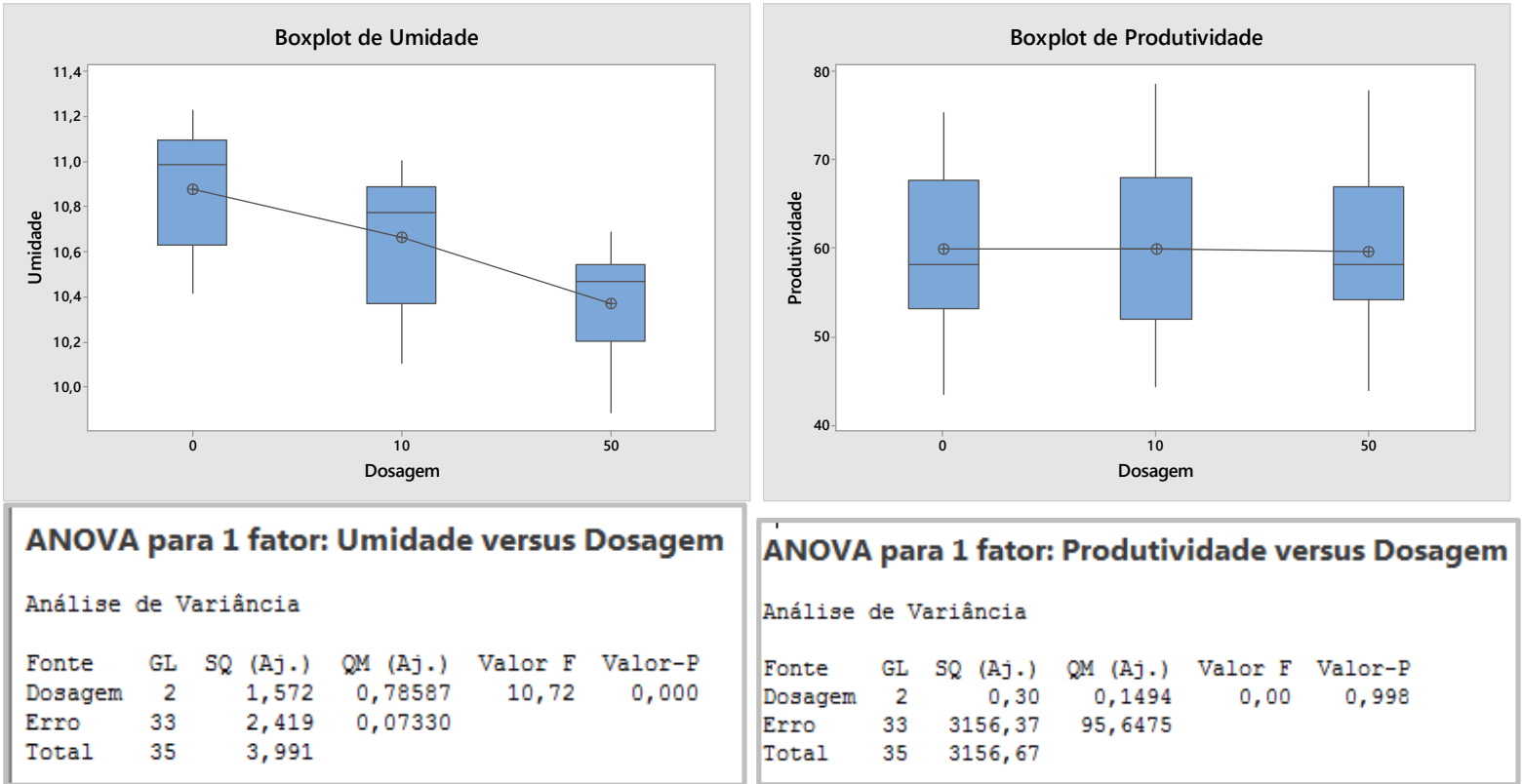

Figura 16: Teste ANOVA de umidade e produtividade - SE $2100 \mathrm{~cm}^{2} / \mathrm{g}$.

A análise de igualdade estatística entre os resultados de umidade e produtividade dos filtros para a superfície específica de $2.400 \mathrm{~cm}^{2} / \mathrm{g}$ mostrou que os resultados de umidade da torta são iguais estatisticamente ( $p$-valor $>0,05$ ), comprovando assim que o surfactante tem pouco impacto para materiais com altíssimas superfícies específicas. Mesmo assim, verificou-se uma redução média do teor de umidade da torta para uma dosagem de $10 \mathrm{ppm}$ do reagente. Os resultados de produtividade apresentaram $p$-valor $>0,05$. Com isto, conclui-se que existe igualdade estatística entre os resultados. Sendo assim, o reagente não impactou na produtividade dos filtros. 

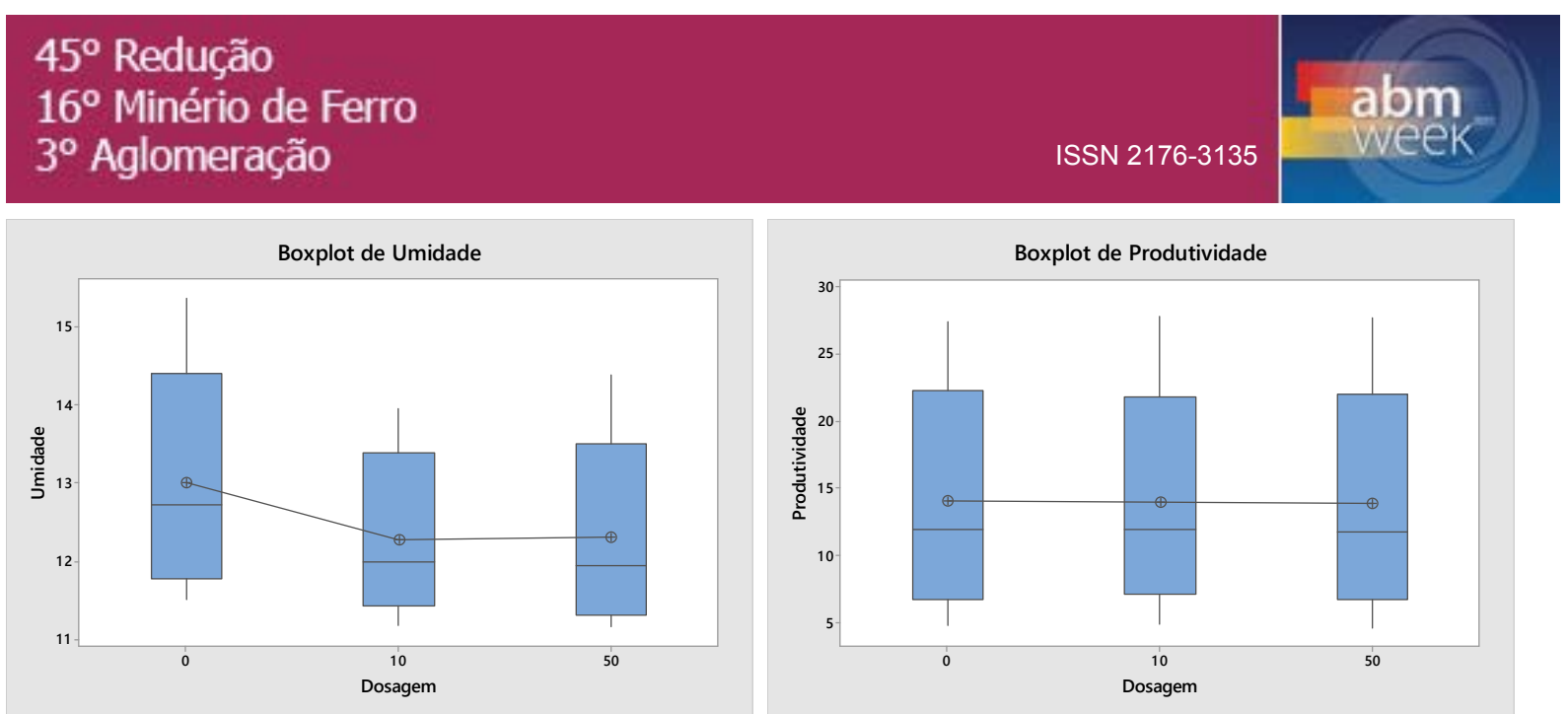

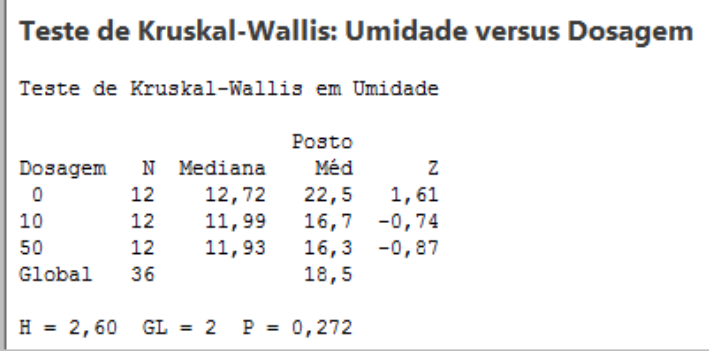

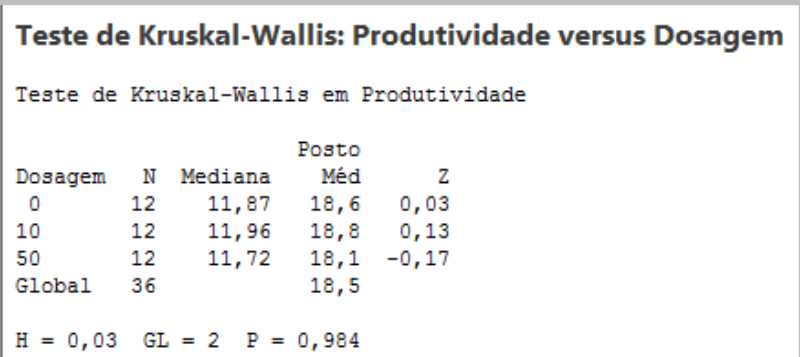

Figura 17: Teste Kruskal-Wallis de umidade e produtividade - SE $2400 \mathrm{~cm}^{2} / \mathrm{g}$.

Os resultados do teste em pelotamento piloto apresentaram bons resultados com relação ao diâmetro médio das pelotas produzidas com o surfactante, além de bons resultados de resistência física das pelotas cruas. Em resumo, o reagente em teste não impactou nos resultados de aglomeração.
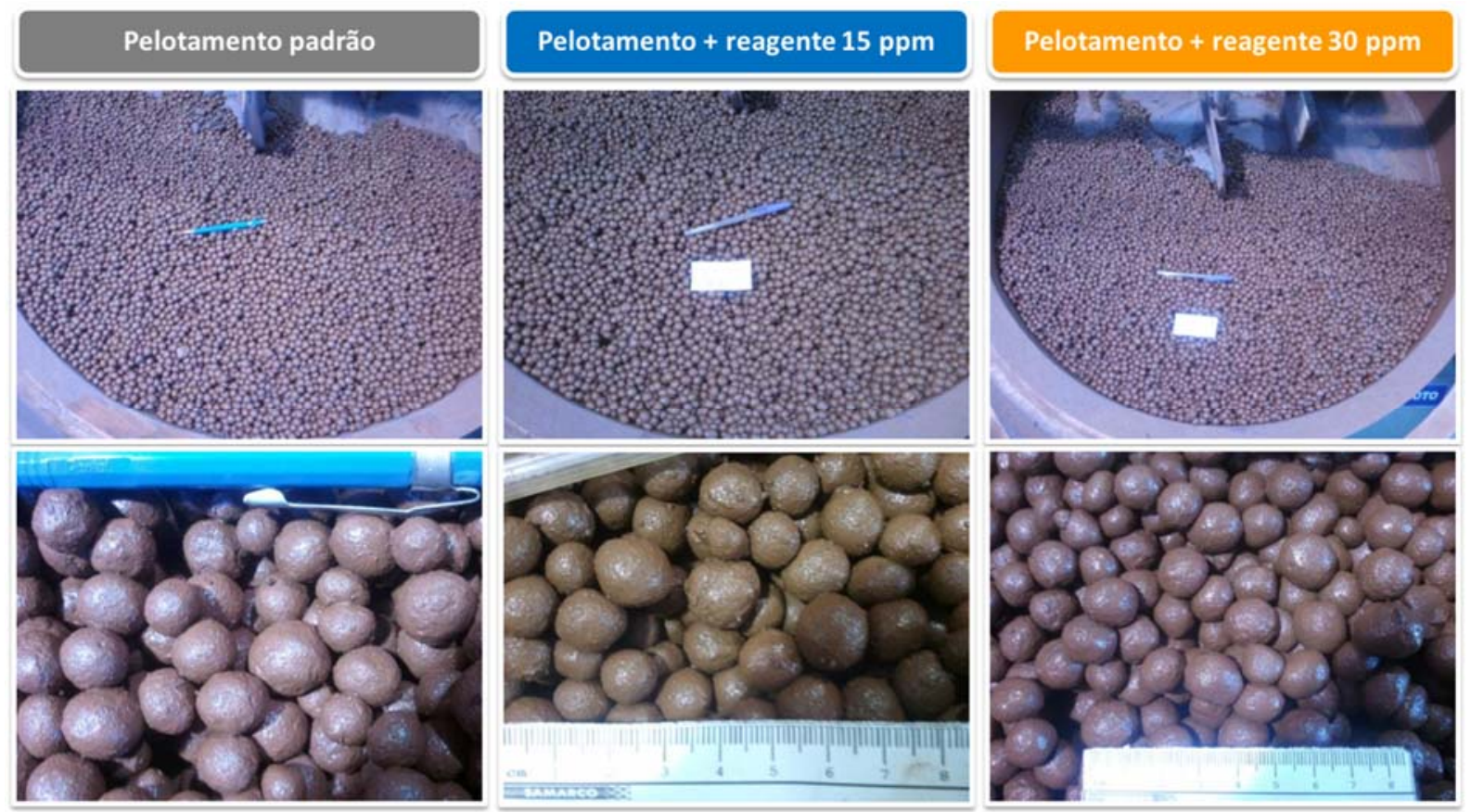

Figura 18: Aspecto visual dos testes de pelotamento.

As próximas figuras apresentam os resultados de granulometria e físico dos testes de pelotamento. 


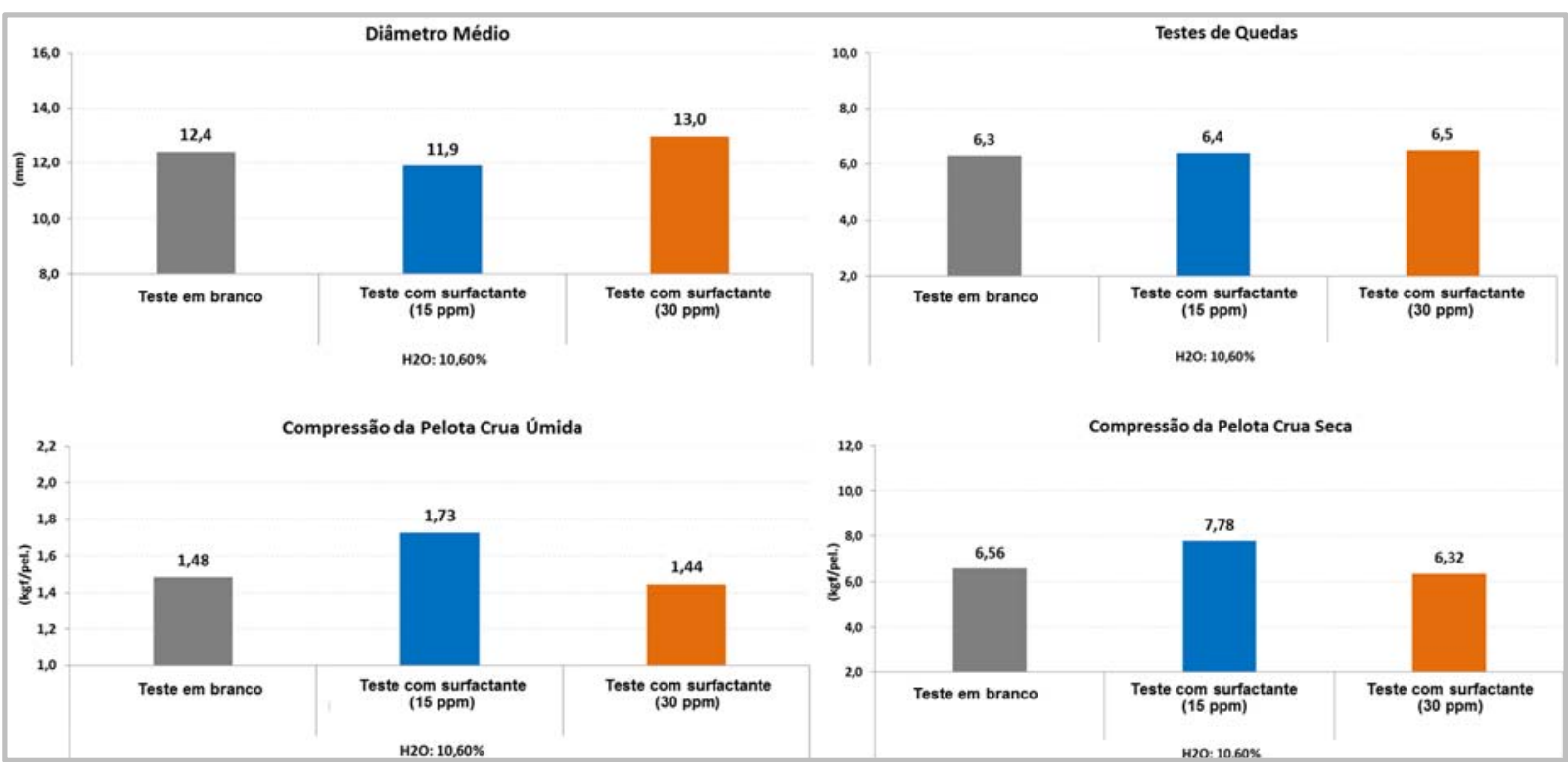

Figura 19: Resultados do teste em pelotamento (diâmetro médio, quedas e compressão).

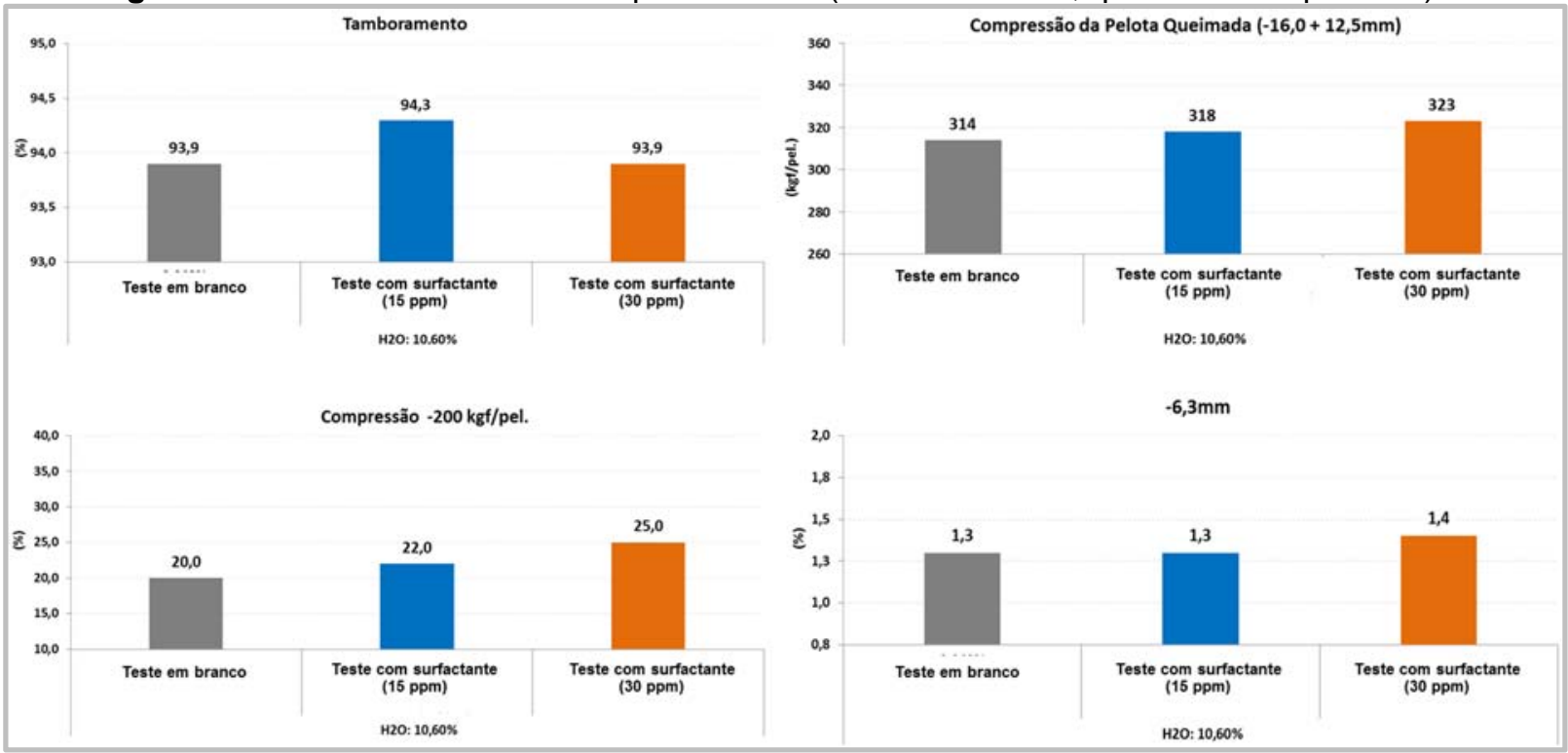

Figura 20: Resultados do teste em pelotamento (tamboramento, compressão e -6,3 mm).

\subsection{Teste Industrial}

Por fim, foram realizados testes industriais com o reagente durante 20 dias, onde o produto foi adicionado na etapa de filtragem de pellet feed. Os resultados industriais mostram um bom comportamento do reagente na redução de umidade da torta formada nos filtros. Vejam que para uma mesma superfície específica, a umidade final do pellet feed foi menor em aproximadamente 0,4 pontos percentuais quando o surfactante foi aplicado. Não foi verificado impacto negativo na etapa de pelotamento. 


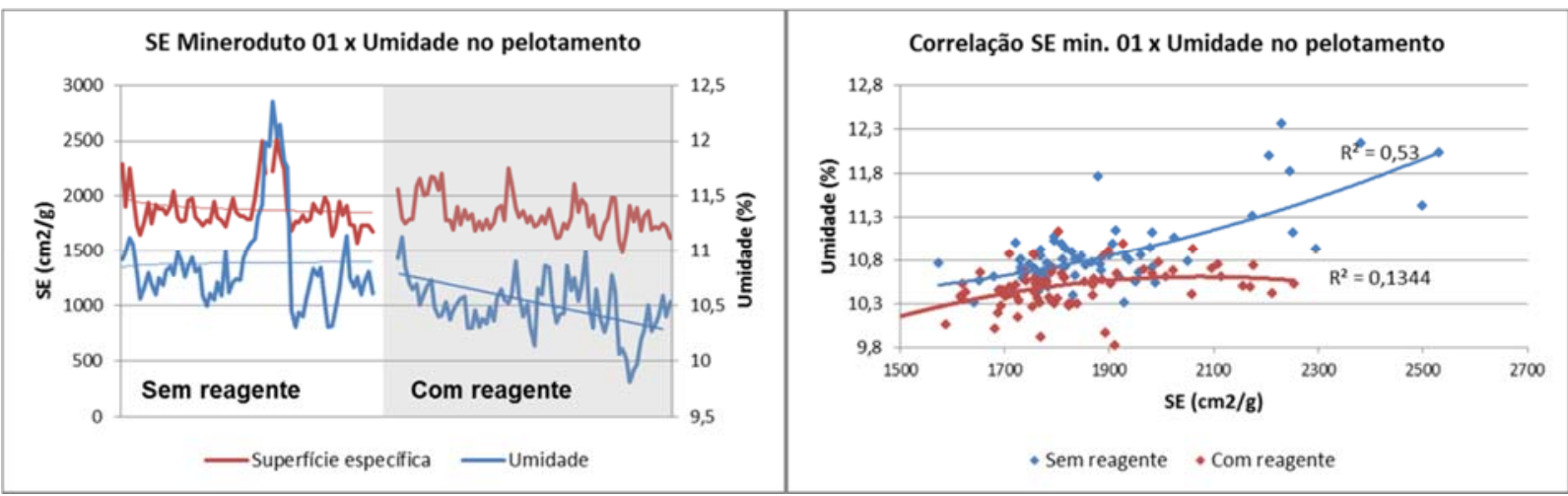

Figura 21: Resultados dos testes industriais.

\section{CONCLUSÃO}

Conclui-se que o reagente apresentou bons resultados em escala piloto, tanto na etapa de filtragem quanto de pelotamento. Nos testes industriais, apresentou uma redução média de umidade em torno de 0,4 pontos percentuais. Portanto, o reagente foi aprovado tecnicamente para utilização nas operações da empresa, preferencialmente para superfícies específicas acima de $1.900 \mathrm{~cm}^{2} / \mathrm{g}$, devido ao acréscimo de custo de utilização do produto.

\section{Agradecimentos}

Agradecemos a todos os envolvidos no trabalho, em especial aos colaboradores dos departamentos de engenharia de processo e de produção da Samarco Mineração em Ponta Ubu.

\section{REFERÊNCIAS}

1 Technical data sheet do produto.

2 JUNIOR, A. M. A., Efeito da adição de reagentes auxiliares na filtragem e suas conseqüências no pelotamento; $39^{\circ}$ Seminário de Redução de Minério de Ferro e Matérias-Primas $/ 10^{\circ}$ Simpósio Brasileiro de Minério de Ferro da ABM, 22 a 26 de novembro de 2009, Ouro Preto, MG, Brasil. 